\title{
MODEL REGRESI COX PROPORTIONAL HAZARD PADA LAJU TAMAT MAHASISWA JURUSAN MATEMATIKA UNIVERSITAS ANDALAS
}

\author{
MARISA, HAZMIRA YOZZA, MAIYASTRI \\ Program Studi Matematika, \\ Fakultas Matematika dan Ilmu Pengetahuan Alam, Universitas Andalas, \\ Kampus UNAND Limau Manis Padang, Indonesia, \\ email : el.marisa15@gmail.com
}

\begin{abstract}
Abstrak. Laju tamat mahasiswa dapat diukur dari lama atau tidaknya seseorang menyelesaikan studi yang dapat dipengaruhi oleh faktor-faktor tertentu. Analisis yang tepat digunakan untuk menganalisis laju tamat tersebut adalah analisis survival. Analisis survival yang digunakan untuk menganalisis hubungan antara variabel-variabel prediktor terhadap waktu survival dapat dilakukan dengan analisis regresi khusus yang menangani data survival dan yang biasa digunakan adalah analisis regresi Cox Proportional Hazard. Data yang digunakan pada penelitian ini adalah data lama studi mahasiswa Jurusan Matematika Universitas Andalas angkatan 2010. Pada penelitian ini diperoleh bahwa faktor-faktor yang signifikan mempengaruhi laju tamat mahasiswa Jurusan Matematika Universitas Andalas angkatan 2010 adalah Indeks Prestasi (IP) semester 2, IP semester 3, IP semester 4, dan jalur masuk Mandiri.
\end{abstract}

Kata Kunci: Laju tamat mahasiswa, analisis survival, analisis regresi Cox Proportional Hazard

\section{Pendahuluan}

Program sarjana merupakan salah satu program jenjang pendidikan tinggi yang idealnya dibutuhkan waktu empat tahun (delapan semester) untuk menyelesaikan jenjang pendidikan ini. Namun kenyataannya tidak semua mahasiswa mampu menyelesaikan jenjang pendidikan ini dalam waktu delapan semester, karena terdapat perbedaan laju tamat atau kelajuan mahasiswa dalam menamatkan studinya yang dapat disebabkan oleh faktor-faktor tertentu. Laju tamat mahasiswa dapat diukur dari lama studi atau lama waktu yang dibutuhkan seorang mahasiswa menyelesaikan studi, sehingga lama studi mahasiswa dipandang sebagai waktu survival. Oleh karena itu analisis yang tepat digunakan untuk menganalisis hubungan antara waktu survival dengan faktor-faktor yang diperkirakan berpengaruh terhadap laju tamat mahasiswa serta menentukan variabel-variabel prediktor yang mempengaruhi laju tamat mahasiswa adalah analisis survival. Metode yang digunakan dalam analisis survival tersebut dapat dilakukan dengan analisis regresi yang khusus menangani data survival dan yang biasa digunakan adalah metode analisis regresi Cox Proportional Hazard. Oleh karena itu pada penelitian ini, peneliti menggunakan metode regresi Cox Proportional Hazard untuk menganalisis hubungan antara waktu survival 
dengan faktor-faktor yang diperkirakan mempengaruhi serta menentukan variabelvariabel yang berpengaruh terhadap laju tamat mahasiswa. Data yang digunakan adalah data lama studi mahasiswa S1 Jurusan Matematika Universitas Andalas angkatan 2010.

\section{Landasan Teori}

\subsection{Analisis Survival}

Analisis survival menggambarkan analisis tahan hidup dari awal waktu penelitian sampai munculnya kejadian tertentu [2]. Variabel utama dalam data analisis survival adalah waktu survival. Waktu survival ini didefinisikan sebagai suatu variabel yang mengukur waktu pengamatan dari suatu titik awal tertentu sampai dengan titik akhir yang ditetapkan. Ada tiga hal yang harus diperhatikan dalam menentukan waktu survival secara tepat, yaitu:

(1) Titik awal adalah waktu dimulainya suatu pengamatan.

(2) Titik akhir adalah kejadian yang menjadi inti dari pengamatan.

(3) Interval waktu adalah interval dari waktu dimulainya penelitian sampai terjadinya suatu kejadian.

\subsection{Fungsi Kepadatan Peluang}

Fungsi kepadatan peluang $f(t)$ didefinisikan sebagai limit peluang individu mengalami kejadian dalam interval yang sangat singkat $(t, t+\Delta t)$ per satuan waktu. Fungsi kepadatan peluang dinyatakan sebagai [5]:

$$
f(t)=\lim _{\Delta t \rightarrow 0} \frac{P[\text { individu mengalami kejadian pada }(t, t+\Delta t)]}{\Delta t} .
$$

\subsection{Fungsi Survival}

Fungsi survival adalah peluang suatu individu akan tetap hidup sampai waktu lebih dari $t$, dimana $t>0$. Fungsi survival dinotasikan dengan $S(t)$. Jika $T$ adalah variabel acak yang menotasikan waktu survival dari suatu individu, maka $S(t)$ dapat didefinisikan sebagai [5]:

$$
\begin{aligned}
S(t) & =P(\text { individu bertahan hidup lebih dari } t) \\
& =P(T>t) \\
& =1-P(T \leq t) .
\end{aligned}
$$

Fungsi survival $S(t)$ adalah fungsi monoton tidak naik, dikatakan fungsi monoton tidak naik apabila $\forall t_{1}<t_{2}$ maka $S\left(t_{1}\right) \geq S\left(t_{2}\right)$ dengan sifat [5]:

(1) $S(t)=1$ untuk $t=0$, artinya peluang individu untuk hidup pada saat $t=0$ adalah 1 .

(2) $S(t)=0$ untuk $t \rightarrow \infty$, artinya peluang individu untuk hidup pada saat $t \rightarrow \infty$ adalah 0 . 


\subsection{Fungsi Hazard}

Fungsi hazard dari waktu survival $T$ didefinisikan sebagai kelajuan suatu individu untuk mengalami kejadian pada interval yang sangat singkat $(t, t+\Delta t)$ dengan syarat individu tersebut bertahan sampai waktu $t$. Fungsi hazard dinyatakan sebagai $[5]$ :

$$
h(t)=\lim _{\Delta t \rightarrow 0} \frac{P(t<T<t+\Delta t \mid T>t)}{\Delta t}
$$

\subsection{Tipe Penyensoran Data}

Dalam analisis survival dikenal tiga jenis penyensoran data, yaitu [5]:

(1) Data Sensor Tipe I.

Pengamatan yang dilakukan selama waktu $t$ yang telah ditentukan dan akan dihentikan setelah batas waktu $t$ berakhir. Apabila setelah batas waktu $t$ berakhir individu tidak mengalami kejadian maka data waktu tersebut dinyatakan sebagai data tersensor tipe I.

(2) Data Sensor Tipe II.

Sensor tipe II adalah tipe penyensoran dimana penelitian akan dihentikan setelah diperoleh $r$ sampel yang mengalami kejadian dalam $\mathrm{n}$ buah objek yang masuk penelitian dengan $(1 \leq r \leq n)$.

(3) Data Sensor Tipe III.

Data sensor tipe III adalah data yang tersensor karena terjadinya kejadian yang bukan menjadi perhatian sebelum batas waktu pengamatan berakhir.

\subsection{Model Regresi Cox Proportional Hazard}

Model regresi Cox Proportional Hazard digunakan untuk mengetahui hubungan antara variabel-variabel prediktor terhadap waktu survival. Fungsi hazard dari individu yang berbeda diasumsikan proporsional setiap waktu [3]. Secara umum model regresi Cox Proportional Hazard dapat dinyatakan sebagai berikut:

$$
h(t, x)=h_{0}(t) \exp \left[\beta_{1} x_{1}+\beta_{2} x_{2}+\beta_{3} x_{3}+\cdots+\beta_{p} x_{p}\right]
$$

dimana

$h(t, x)$ : kelajuan suatu individu mengalami kejadian pada waktu t dengan karakteristik $\left(x=x_{1}, x_{2}, \cdots, x_{p}\right)$,

$h_{0}(t)$ : fungsi hazard dasar (baseline hazard function), yaitu nilai fungsi hazard pada saat semua variabel prediktor bernilai 0 dan tidak bergantung pada karakteristik x, hanya melibatkan waktu survival t,

dan $\beta^{T}=\left[\beta_{1}, \beta_{2}, \cdots, \beta_{p}\right]$ adalah vektor koefisien regresi atau vektor parameter, dimana $\beta_{1}, \beta_{2}, \cdots, \beta_{p}$ ditentukan dengan menggunakan metode Maximum Likelihood. 


\subsection{Pengujian Parameter}

Uji signifikansi parameter model dilakukan menggunakan uji Likelihood Ratio dan uji Wald.

(1) Uji Likelihood Ratio.

Uji Likelihood Ratio atau disebut juga uji $G$ merupakan pengujian yang dilakukan untuk melihat apakah variabel prediktor secara bersama-sama berpengaruh terhadap model. Statistik uji $G$ adalah:

$$
G=-2\left(\log L_{0}-\log L_{p}\right),
$$

dengan:

$L_{0}$ : likelihood dari model tanpa variabel prediktor,

$L_{p}$ : likelihood dari model yang terdiri dari $\mathrm{p}$ variabel prediktor.

Statistik uji $G$ mengikuti sebaran khi-kuadrat $\left(\chi^{2}\right)$ dengan derajat bebas $p$, jika $G>X_{(\alpha, p)}^{2}$ maka tolak $H_{0}$, ada $\beta_{j} \neq 0$ berarti terdapat paling tidak satu variabel prediktor yang berpengaruh nyata terhadap model. Jika $G \leq X_{(\alpha, p)}^{2}$ maka tidak tolak $H_{0}$.

(2) Uji Wald.

Uji Wald digunakan untuk menguji pengaruh masing-masing variabel prediktor terhadap model. Pengujian dilakukan untuk setiap variabel prediktor $X_{j}(j=1,2, \cdots, p)$. Hipotesis pada uji ini adalah:

$$
\begin{aligned}
& H_{0}: \beta_{j}=0, \\
& H_{1}: \beta_{j} \neq 0 .
\end{aligned}
$$

Statistik uji Wald adalah:

$$
X_{W}^{2}=\left(\frac{\beta_{j}}{\left(S E\left(\beta_{j}\right)\right)}\right)^{2},
$$

dengan $S E\left(\beta_{j}\right)$ adalah nilai galat baku (standard error) koefisien regresi ke- $j$. Statistik uji Wald mengikuti sebaran khi-kuadrat $\left(\chi^{2}\right)$ dengan derajat bebas 1 . Kriteria pengambilan keputusan yaitu jika $\chi_{W}^{2}>\chi_{(\alpha, 1)}^{2}$ maka tolak $H_{0}$, ada $\beta_{j} \neq 0$ berarti variabel prediktor $X_{j}$ berpengaruh nyata terhadap model. Jika $\chi_{W}^{2} \leq \chi_{(\alpha, p)}^{2}$ maka tidak tolak $H_{0}$.

\subsection{Pendugaan Parameter Model}

Untuk menduga parameter $\beta$ pada model regresi Cox Proportional Hazard digunakan metode Maximum Likelihood. Misalkan dari $n$ pengamatan terdapat $r$ individu yang mengalami kejadian sehingga terdapat $n-r$ individu yang tersensor. Apabila individu yang mengalami kejadian diurutkan berdasarkan waktu kejadian maka urutannya menjadi $t_{1}<t_{2}<t_{3}<\cdots<t_{r}$.

Misalkan variabel prediktor dari individu yang mengalami kejadian pada saat $t_{i}$ (urutan kejadian ke- $i$ ) dinotasikan dengan $\mathbf{x}_{i}=\left(x_{i 1}, x_{i 2}, \cdots, x_{i p}\right)$. Maka peluangnya adalah:

$P$ ( individu dengan variabel $\mathbf{x}_{i}$ mengalami kejadian saat $t_{i} \mid$ satu kejadian saat $t_{i}$ ). 
Misalkan $A$ adalah individu-individu dengan variabel $\mathbf{x}_{i}$ yang mengalami kejadian saat $t_{i}$ dan $B$ adalah satu kejadian saat $t_{i}$, maka persamaan diatas menjadi:

$$
\begin{aligned}
P(A \mid B) & =\frac{(P(A \cap B))}{(P(B))} \\
& =\frac{P\left(\text { individu dengan variabel } \mathbf{x}_{i} \text { mengalami kejadian saat } t_{i}\right)}{P\left(\text { satu kejadian pada saat } t_{i}\right)}
\end{aligned}
$$

Dengan mengambil hasil peluang bersyarat dari Persamaan (2.7) diperoleh fungsi likelihood:

$$
L(\beta)=\prod_{i=1}^{r} \frac{\left.\exp \left(\sum_{j=1}^{p}\right) \beta_{j} x_{j(i)}\right)}{\sum_{l \in R\left(t_{i}\right)} \exp \left(\sum_{j=1}^{p} \beta_{j} x_{j(l)}\right)}
$$

Selanjutnya untuk memperoleh hasil pendugaan parameter $\beta_{j}$ pada model regresi Cox Proportional Hazard dapat dilakukan dengan memaksimumkan natural log dari fungsi likelihood (2.7).

\subsection{Uji Asumsi Regresi Cox Proportional Hazard}

Dalam model regresi Cox Proportional Hazard ada sebuah asumsi yang harus terpenuhi, yaitu asumsi Proportional Hazard (PH). Pemeriksaan asumsi dapat dilakukan secara visual menggunakan grafik plot $\log (-\log [S(t, x)])$. Apabila plot dari masing-masing kategori dari variabel kategorik terlihat sejajar atau berimpit maka dapat dikatakan asumsi PH terpenuhi. Dan apabila plot dari masing-masing kategori bersilang maka asumsi $\mathrm{PH}$ tidak terpenuhi dan variabel prediktor tersebut tidak dapat dimasukkan ke dalam model [4].

\subsection{Hazard Ratio}

Hazard Ratio adalah perbandingan kelajuan suatu kejadian yang dialami oleh satu kelompok individu dengan kelajuan kejadian yang dialami oleh kelompok individu lainnya. Hazard Ratio didefinisikan sebagai:

$$
H R=\frac{\left(h\left(t, \mathbf{x}^{*}\right)\right)}{(h(t, \mathbf{x}))}
$$

dimana

$$
\begin{aligned}
H R & : \text { Hazard Ratio, } \\
\mathbf{x}^{*} & =\left(x_{1}^{*}, x_{2}^{*}, \cdots, x_{p}^{*}\right), \\
\mathbf{x} & =\left(x_{1}, x_{2}, \cdots, x_{p}\right) .
\end{aligned}
$$

\section{Data dan Metode Penelitian}

Data yang digunakan pada penelitian ini adalah data lama studi mahasiswa Jurusan Matematika Universitas Andalas angkatan 2010 dalam menyelesaikan pendidikan S1 serta variabel-variabel yang diperkirakan berpengaruh. Variabel yang digunakan dalam penulisan ini adalah waktu survival berupa lama studi mahasiswa dan variabel prediktornya adalah Indeks Prestasi Semester 1, Indeks Prestasi Semester 2, 


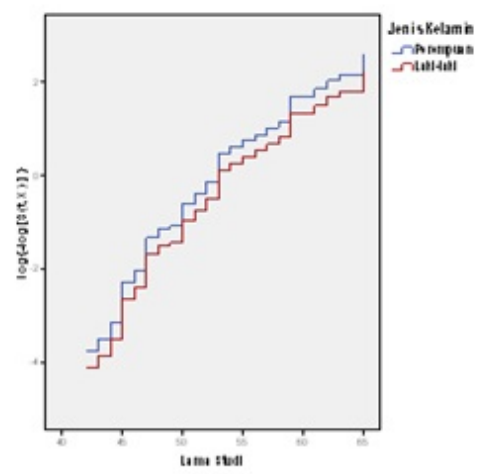

(a)

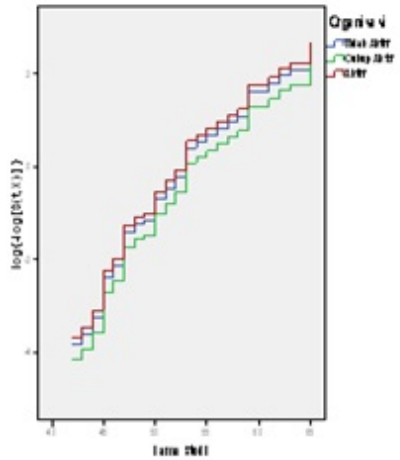

(b)

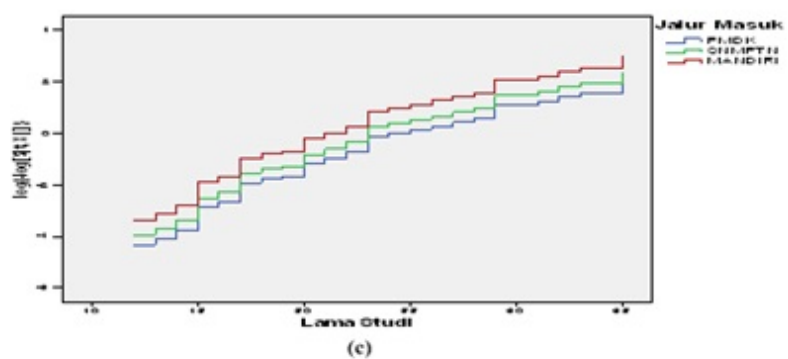

Gambar 1: Grafik $\log \{-\log [S(t, \boldsymbol{x})]\}$ Variabel Jenis Kelamin, Organisasi, dan Jalur Masuk terhadap Waktu Survival

Indeks Prestasi Semester 3, Indeks Prestasi Semester 4, Jenis Kelamin, Organisasi, Jalur Masuk, dan jumlah SKS kumulatif.

Penelitian ini dilakukan dengan langkah-langkah sebagai berikut:

(a) Melakukan analisis deskriptif terhadap data.

(b) Melakukan uji asumsi Proportional Hazard $(\mathrm{PH})$ pada variabel kategorik.

(c) Apabila uji asumsi Proportional Hazard terpenuhi selanjutnya tentukan estimasi parameter model dengan menggunakan metode Maximum Likelihood estimation.

(d) Setelah mendapatkan model regresi Cox Proportional Hazard dilakukan pengujian signifikansi parameter, dengan dua cara yaitu uji Likelihood Ratio dan uji Wald dan hitung nilai Hazard Ratio.

\section{Pembahasan}

Dari 89 orang mahasiswa matematika angkatan 2010 terdapat 14 orang mahasiswa yang tidak dapat diamati secara utuh, karena individu tersebut keluar atau hilang sebelum batas pengamatan berakhir, sehingga dapat disimpulkan bahwa individu tersebut tersensor tipe III. Sebelum mendapatkan model regresi Cox Proportional Hazard dilakukan uji asumsi PH dan diperoleh hasil seperti pada Gambar 1.

Dari Gambar 1 dapat dilihat bahwa grafik $\log (-\log [S(t, x)])$ sejajar maka 
Tabel 1: Pengujian Signifikansi Parameter dengan Uji Wald

\begin{tabular}{|c|c|c|c|c|}
\hline Variabel & $\beta$ & Wald $\left(\mathrm{X}_{\mathrm{W}}^{2}\right)$ & P-value & Keputusan \\
\hline IP_1 & 0.373 & 1.123 & 0.288 & Tidak Signifikan \\
\hline IP_2 & 1.503 & 5.802 & 0.016 & Signifikan \\
\hline IP_3 & 1.241 & 8.731 & 0.003 & Signifikan \\
\hline IP_4 & 0.796 & 4.704 & 0.030 & Signifikan \\
\hline JK & -0.353 & 0.989 & 0.32 & Tidak Signifikan \\
\hline O(1) & -0.321 & 0.468 & 0.494 & Tidak Signifikan \\
\hline O (2) & 0.151 & 0.113 & 0.738 & Tidak Signifikan \\
\hline JM(1) & 0.386 & 1.112 & 0.291 & Tidak Signifikan \\
\hline JM(2) & 0.977 & 6.244 & 0.013 & Signifikan \\
\hline Jumlah Sks & 0.006 & 0.016 & 0.896 & Tidak Signifikan \\
\hline
\end{tabular}

asumsi PH terpenuhi, selanjutnya dilakukan pengolahan data untuk mendapatkan model. Dengan menganggap semua variabel prediktor berpengaruh pada model maka estimasi model menjadi:

$$
\begin{aligned}
\hat{h}(t, x) & =\hat{h}_{0}(t) \exp \left[\beta_{1} x_{1}+\beta_{2} x_{2}+\beta_{3} x_{3}+\cdots+\beta_{10} x_{10}\right] \\
& =\hat{h}_{0}(t) \exp \left[0.373 I P_{1}+1.503 I P_{2}+1.241 I P_{3}+0.796 I P_{4}-0.353 J K\right. \\
& -0.321 O(1)+0.151 O(2)+0.386 J M(1)+0.977 J M(2)+0.006 S K S] .
\end{aligned}
$$

Pengujian Likelihood Ratio dilakukan untuk melihat apakah variabel prediktor berpengaruh secara bersama-sama terhadap model. Uji hipotesis untuk pengujian ini adalah:

$$
\begin{aligned}
& H_{0}: \beta_{1}=\beta_{2}=\beta_{3}=\cdots=\beta_{10}=0, \\
& H_{1}: \text { terdapat } \beta_{j} \neq 0, j=1,2,3, \cdots, 10 .
\end{aligned}
$$

Taraf signifikansi $(\alpha)$ yang digunakan adalah 0.05 , dan dari pengolahan data diperoleh nilai $-2 \log L_{0}=516.945$ dan nilai $-2 \log L_{p}=436.160$. Sehingga nilai $G$ dapat dihitung dengan:

$$
\begin{aligned}
G & =-2\left(\log L_{0}-\log L_{p}\right) \\
& =516.945-436.160 \\
& =80.785 .
\end{aligned}
$$

Nilai $X_{0.05,10}^{2}$ tabel adalah 18.307. Karena $G>X_{0.05,10}^{2}$ maka tolak $H_{0}$, dapat disimpulkan bahwa terdapat sekurang-kurangnya satu variabel prediktor yang berpengaruh signifikan terhadap model regresi Cox Proportional Hazard. Karena terdapat variabel prediktor yang berpengaruh signifikan terhadap model, selanjutnya dilakukan pengujian signifikansi masing-masing parameter terhadap model dengan uji Wald dan diperoleh hasil pada Tabel 1.

Dapat dilihat bahwa variabel $I P_{2}, I P_{3}, I P_{4}$, dan $J M(2)$ berpengaruh signifikan terhadap model. Sehingga diperoleh model regresi Cox Proportional Hazard sebagai 
Tabel 2: Perhitungan Rasio Hazard untuk Variabel Signifikan

\begin{tabular}{|c|c|c|}
\hline Variabel & $\beta$ & $\operatorname{EXP}(\beta)$ \\
\hline IP_2 & 1.503 & 4.495 \\
\hline IP_3 & 1.241 & 3.459 \\
\hline IP_4 & 0.796 & 2.216 \\
\hline Jalur_Masuk(2) & 0.977 & 2.656 \\
\hline
\end{tabular}

berikut:

$$
\begin{aligned}
h(t, x) & =h_{0}(t) \exp \left[\beta_{1} x_{1}+\beta_{2} x_{2}+\beta_{3} x_{3}+\cdots+\beta_{p} x_{p}\right] \\
& =h_{0}(t) \exp \left[1.503 I P_{2}+1.241 I P_{3}+0.796 I P_{4}+0.977 J M(2)\right]
\end{aligned}
$$

Setelah model regresi Cox Proportional Hazard diperoleh, selanjutnya dihitung nilai rasio hazard untuk variabel yang signifikan, dan diperoleh hasil seperti pada Tabel 2.

Dapat dilihat dari Tabel 2 bahwa nilai $\exp (\beta)$ untuk variabel $I P_{2}$ adalah 4.495 , dapat diinterpretasikan apabila nilai $I P_{2}$ naik sebesar 1 satuan maka laju tamat mahasiswa akan bertambah sebesar 4.495 kali. Nilai $\exp (\beta)$ untuk $I P_{3}$ adalah 3.459 , apabila nilai IP semester 3 naik sebesar 1 satuan maka laju mahasiswa mencapai kelulusan bertambah 3.459 kali. nilai $\exp (\beta)$ untuk variabel $I P_{4}$ adalah 2.216, apabila nilai IP semester 4 naik sebesar 1 satuan maka laju mahasiswa mencapai kelulusan bertambah 2.216 kali. Nilai $\exp (\beta)$ untuk untuk variabel $J M(2)$ adalah 2.656, artinya mahasiswa yang masuk melalui jalur Mandiri memiliki laju tamat lebih besar 2.656 kali dibanding mahasiswa yang masuk melalui jalur PMDK dan SNMPTN.

\section{Kesimpulan}

Berdasarkan hasil analisis pengolahan data tentang faktor-faktor yang mempengaruhi laju tamat mahasiswa matematika angkatan 2010 dapat disimpulkan bahwa variabel prediktor $I P_{2}, I P_{3}, I P_{4}$, dan jalur masuk Mandiri memiliki pengaruh yang signifikan terhadap laju tamat mahasiswa. Sehingga model akhir regresi Cox Proportional Hazard adalah:

$$
\begin{aligned}
h(t, x) & =h_{0}(t) \exp \left[\beta_{1} x_{1}+\beta_{2} x_{2}+\beta_{3} x_{3}+\cdots+\beta_{p} x_{p}\right], \\
& =h_{0}(t) \exp \left[1.503 I P_{2}+1.241 I P_{3}+0.796 I P_{4}+0.977 J M(2)\right]
\end{aligned}
$$

\section{Daftar Pustaka}

[1] Bain, L.J dan M. Engelhardt. 1992. Introduction to Probability and Mathematical Statistic, Second edition. Duxburry Press, California.

[2] Collet, D. 2004. Modelling Survival data in Medical Research. Second edition. Chapman dan Hall, London. 
Model Regresi Cox Proportional Hazard pada Laju Tamat Mahasiswa 41

[3] Hutahaean, L.P., M.A. Mukid dan T. Wuryandari. 2014. Model Cox Proportional Hazard Pada Data Lama Studi Mahasiswa. Jurnal Gaussian 3(2): 173 $-181$.

[4] Kleinbaum, D.G. dan Klein, M. 2005. Survival Analysis a Self-Learning Text. Springer, New York.

[5] Lee, E. T dan Wang, J. W. 2003. Statistical Methods for Survival Data Analysis. John Wiley dan Sons, Inc, Canada. 